\title{
CRISES DO CAPITALISMO E POSSIBILIDADES DE TRANSIÇÃO DA VELHA FORMA ${ }^{1}$
}

\section{Luciana Raimundo ${ }^{2}$}

\section{INTRODUÇÃO}

O presente artigo objetiva problematizar o sistema capitalista contemporâneo, empregando, para tanto, a análise marxiana referente ao desenvolvimento das condições históricas necessárias para a transição da velha a uma nova forma de sociedade. Nesse sentido, considero transição como o processo em que uma sociedade, com uma nova forma de ser social, se constitui a partir da sociedade anterior, carregando, contudo, o peso do passado ainda não totalmente superado (MARX, 2011).

Para dar início a minha argumentação, descrevo, primeiramente, dois períodos de crises globais ocorridos em consequência do modelo econômico dominante. O primeiro refere-se à crise vivenciada nas décadas de 1970 e 1980, culminando em uma reestruturação produtiva e acumulativa, e redefinindo as divisas entre centro e periferia do sistema capitalista. $\mathrm{O}$ segundo relaciona-se à crise do sistema financeiro, com ápice em 2008, bem como sua repercussão global. Na sequência, discorro sobre as consequências desta última no Brasil e as ações do governo de Dilma Rousseff na contenção dos distúrbios evidenciados.

Diante do panorama disposto acima, reflito sobre a crise do sistema financeiro a partir de Marx, analisando as gestões neoliberais e as políticas keynesianas assumidas pelos países no centro da economia mundial. Aponto alternativas situadas no campo da Economia Solidária e das Finanças Solidárias, formadas dentro e a partir do sistema capitalista, como estratégia de desenvolvimento das condições históricas necessárias

1 O conteúdo deste artigo trata-se de uma versão preliminar de um dos capítulos de minha dissertação de mestrado, provisoriamente intitulada Finanças Solidárias e a luta contra hegemônica: um estudo de caso do Banco Comunitário União Sampaio e da Agência Popular Solano Trindade, em fase de conclusão.

2 Mestranda do Programa de Pós-graduação em Sociologia - PPGSP/UFSC. Licenciada e bacharel em Ciências Sociais pela Universidade Federal de Santa Catarina. Contato: veialatina@gmail.com. 
para a transformação nos âmbitos social, econômico e político, considerando seus alcances e limites.

\section{CRISES DO CAPITALISMO E SUAS CONTRADIÇÕES}

Entre as décadas de 1940 e 1970, período pós Segunda Guerra Mundial, verificou-se o elevado crescimento econômico dos países "desenvolvidos" e a supremacia tecnológica estadunidense. Os modelos produtivos fordista e taylorista possibilitaram o aumento da oferta de produtos, assim como a redução de seus preços para o consumidor final. O aumento da exploração do trabalho, com longas jornadas e baixos salários, assim como a aplicação de determinadas tecnologias, facilitaram o aumento dos lucros. Contudo, uma superprodução aliada à estagnação econômica, ocasionado pelo baixo poder aquisitivo dos consumidores/trabalhadores, culminaram em disjunções sistêmicas. A queda na taxa de lucro, conforme descrita por Marx (1996, p.77-83), foi uma das responsáveis pela crise estrutural do sistema capitalista nas décadas de 1970 e 1980.

Sendo assim, mudanças necessárias nos padrões de produção e acumulação foram situadas em uma perspectiva reformista, ou seja, sem considerar uma transformação radical nas bases produtivas. O Toyotismo ${ }^{3}$, apresentado como possibilidade de enfrentamento da crise produtiva, inovou com o sistema Just in time. Tal sistema visa produzir o necessário e no momento adequado, por meio da multifuncionalização da mão de obra e da implantação do controle de qualidade total. Adequado às necessidades do capital, o modelo avançou primeiramente na Inglaterra, Estados Unidos e Alemanha, iniciando um processo de reconfiguração produtiva mundial.

Medidas que visavam modificações na balança comercial, como o aumento das importações e a diminuição das exportações, também foram implantadas. Polos produtivos foram gradativamente transferidos para a periferia do capital, ou seja, para

$3 \mathrm{O}$ toyotismo tem origem na fábrica da Toyota no Japão. Foi desenvolvido pelo japonês Taiichi Ohno e adquiriu projeção global, principalmente após a Segunda Guerra Mundial. 


\section{T

países em desenvolvimento, normalmente caracterizados por mão de obra barata e por movimento operário frágil. Milhares de postos de trabalho formais foram eliminados das regiões originais, tornando o emprego uma prerrogativa de trabalhadores em posse de conhecimento científico e tecnológico de ponta. Empregados, antes beneficiados por legislação específica, passaram a vivenciar as consequências da "flexibilização"4 dos seus direitos, naturalizando em seus cotidianos a insegurança e a competição. À massa de trabalhadores desempregados e desqualificados somaram-se os trabalhadores desempregados provenientes das inúmeras empresas capitalistas que, não adaptadas ao novo modelo produtivo, decretaram falência.

A reavaliação dos padrões acumulativos tornou sedutora a aplicação de capital no setor financeiro. A insegurança num período de reestruturação produtiva impulsionou milhares de investidores à compra de ações e títulos, a fïm de garantirem seus rendimentos por meio do recebimento de juros. O ajuste das políticas econômicas em consonância com a nova tendência de acumulação ocorreu no início da década de 1970, quando a moeda norte-americana perdeu oficialmente seu lastro real. O sistema Breton Woods estabelecido ao final da Segunda Guerra Mundial entre países aliados, estabelecendo que as moedas dos países membros tivessem paridade com dólar e a moeda norte-americana ao ouro, chegou ao fim. Richard Nixon decretou que bancos estrangeiros não poderiam exigir a conversão do dólar em ouro. Dessa forma, o mundo industrializado passou a trabalhar com a moeda fiduciária ${ }^{5}$ e inconversível, dependendo unicamente do controle dos governos nacionais para ter sua emissão e multiplicação organizadas (SOARES, 2006, p.117).

As políticas econômicas lideradas por Ronald Reagan e Margareth Thatcher na década de 1980 proporcionaram liberdade para as instituições financeiras atuarem em mercados antes reservados aos grandes bancos comerciais. A consequente globalização financeira possibilitou maior atuação destas instituições fora de suas fronteiras originais, aumentando a competição por novos mercados domésticos ${ }^{6}$. O crescimento vertiginoso

4 A flexibilização é entendida aqui como uma série de normas e condições de trabalho ajustadas às mutações econômicas e sociais, reduzindo ou mesmo suprimindo as vantagens concedidas aos trabalhadores.

5 Qualquer título não conversível ou lastreado em metais, como o ouro e a prata. Constituem-se principalmente por cheques, ordens de pagamentos, títulos de crédito entre outros.

6 Equivalente a mercados nacionais. 


\section{Tese}

de grandes corporações, holdings, conglomerados, instituições financeiras e mistas reconfiguraram os mercados de investimento, produtivo e consumidor (CARVALHO, 2008, p.1).

Na década de 1990, como estratégia para a conquista desses novos mercados, recursos financeiros foram destinados, em caráter de empréstimo, aos países considerados emergentes. Problemas no pagamento destes empréstimos, como os ocorridos com o México em 1994, a Ásia, a Rússia e o Brasil, evidenciaram os riscos latentes destes mercados. Doravante, o investimento no mercado imobiliário dos Estados Unidos, cujo estoque de hipotecas chegava a cerca de 10 trilhões de dólares, metade das quais contava com o suporte de empresas paraestatais como Fannie Mae e Freddie Mac, passou a ser um dos principais focos de atuação das instituições financeiras.

A nova estratégia levava em consideração que contratos de financiamento, de compra de residências e de hipotecas residenciais possuíam longa duração. $\mathrm{O}$ comprador se tornaria o proprietário definitivo quando o pagamento fosse quitado e, havendo inadimplência, o financiador retomaria o imóvel, podendo revendê-lo para reverter o prejuízo. A fim de consolidar os empréstimos, bancos e instituições financeiras realizaram análises detalhadas da renda, do histórico de crédito e das perspectivas profissionais dos candidatos, supostamente aumentando a segurança na efetivação dos pagamentos. Pessoas com análises negativas foram classificadas como subprimes, ou seja, tomadores de empréstimos que não ofereciam garantias suficientes para efetivação da transação.

Análises minuciosas do comportamento econômico dos norte-americanos entre 1980 e 2006, aproximadamente, identificavam uma sustentável prosperidade, mesmo após duas leves e rápidas recessões que interromperam o crescimento da economia naquele país. Pesquisas confirmaram que os norte-americanos com empregos fixos e trabalhos informais mantiveram renda estável no período investigado. Com base nesses estudos, a análise necessária para a liberação de crédito passou a pautar-se em modelos quantitativos, prevendo a probabilidade de sucesso do empréstimo (CARVALHO, 2008, p.18). 


\section{Tese}

Enxergando as hipotecas subprimes como nicho de mercado, bancos e instituições financeiras aumentaram a segurança do investimento junto às agências de seguro por meio da securitização ${ }^{7}$. De acordo com Farhi, Prates, Freitas e Cintra (2008, p.25), ao auxiliar as instituições financeiras na montagem dos "pacotes de crédito" que lastreavam títulos securitizados, as agências de seguro sustentaram a predição de que ativos de crédito bancário poderiam ser precificados e negociados como sendo de "baixo risco" em mercados secundários. Em consequência, as operações de securitização de dívidas estreitaram as conexões entre os mercados de crédito e de capitais $^{8}$, já que grande parte do que se negocia neste último depende, indiretamente, do desempenho do primeiro. Na crise norte-americana recente, assim como na crise asiática no final da década de 1990, este processo contribuiu decisivamente para encurtar o tempo que separa os primeiros sinais de frustração das expectativas de um quadro generalizado de deflação de ativos.

Bancos procuraram retirar os riscos de seus balanços utilizando os swaps $^{9}$ já existentes, e o Shadow Banking System passaram a utilizar novos mecanismos de exposição aos riscos e rendimentos do mercado de crédito. O Shadow Banking System - um aglomerado de instituições financeiras funcionando como banco - captava recursos no curto prazo e investia em ativos de longo prazo e líquidos, sendo pouco regulado e supervisionado, sem reservas de capital, sem acesso aos seguros de depósitos, às operações de redesconto e às linhas de empréstimos de última instância dos bancos centrais. Por essas características, era completamente vulnerável a uma corrida de investidores, mediante saque dos recursos por desconfiança dos aplicadores, ou por desiquilíbrios patrimoniais por meio da desvalorização dos ativos (CINTRA e FARHI, 2009, p.282).

\footnotetext{
7 Entende-se aqui a securitização como uma ferramenta usada na conversão de ativos em títulos mobiliários passíveis de negociação. Transformam-se ativos ilíquidos em títulos mobiliários líquidos, transferindo os riscos associados para investidores que os compram. Na prática, na securitização, a dívida é transferida e vendida na forma de títulos, para vários investidores.

8 Constitui-se das bolsas de valores, das sociedades corretoras e de outras instituições financeiras.

9 São operações em que há troca de posições quanto ao risco e rentabilidade entre investidores. O contrato de troca pode ter como objeto moedas commodities ou ativos financeiros. Cf.: www.infomoney.com.br/educacao/guias/noticia/377126/swaps-que-sao-como-funcionam-operacoestroca-fluxo-caixa Acesso em 01/08/2014.
} 
A expansão econômica, caracterizada por um período de "crescimento sem emprego", levou o Federal Reserve System (FED) a reduzir as taxas de juros, mantendo-as baixas por um período para, posteriormente, aumentá-las de forma lenta e gradual (PALLEY, 2010, p.8). Ao final de 2006, as hipotecas apresentaram reajustes, impossibilitando a efetivação de alguns pagamentos. Segundo Carvalho (2009, p.19), a crise iniciada não se deve simplesmente aos movimentos da política monetária, embora o aumento na taxa de juros pelo FED em 2006 tenha agravado as inadimplências das hipotecas subprimes. O autor acredita que mesmo sem o ajuste das taxas a crise teria ocorrido.

A primeira fase da crise, segundo Hermann (2008, p.30) ocorreu com as tentativas de venda destes ativos. Portadores dos títulos das dívidas das hipotecas subprimes iniciaram uma corrida para desfazerem-se desses títulos, contudo, sem novos compradores, deram-se conta do risco a que estavam expostos. A incerteza quanto à extensão dos problemas levou a uma rápida elevação da preferência por liquidez e ao consequente colapso dos preços de ativos menos líquidos, induzindo a crise a uma nova fase: falta de liquidez. Para Hermann (2008, p.30), um quadro de crise financeira sistêmica só se configura se a crise de crédito der origem a uma crise de confiança. Esta frustrou as expectativas de renda futura daqueles que assumiram dívidas, e também as expectativas de retorno-risco daqueles que adquiriram tais ativos financeiros. Assim, os preços dos títulos desabaram e deram início à terceira fase desta crise: a crise patrimonial.

Empresas, bancos e instituições financeiras possuem passivos e ativos. Uma empresa se torna insolvente quando os valores dos seus ativos caem, deixando seu capital negativo. Neste cenário, duas tendências geram distintas repercussões. A primeira seria decretar falência ou sofrer intervenção estatal, ou ainda ser vendida para empresas que precisam ser pressionadas ou favorecidas pelo governo, como aconteceu com Bear Stearns, a Merrill Lynch, a AIG, a Fannie Mae e o Freddie Mac. A segunda seria a retração, isto é, empresta-se menos. Consequentemente, as empresas ficam sem capital para produzir e os consumidores não consomem bens duráveis porque não há crédito. Na análise de Carvalho (2008, p.21), esta segunda tendência provoca o 


\section{Tese}

esfriamento e a desaceleração da economia, implicando o aumento do desemprego e forte recessão.

Em uma crise de crédito clássica os danos, bem como sua distribuição, seriam conhecidos, segundo Farhi, Prates, Freitas e Cintra (2008, p.23). Na atual configuração do sistema financeiro, os derivativos de crédito e os produtos lastreados em crédito imobiliário multiplicaram os prejuízos por um fator desconhecido. Redistribuíram os riscos de maneira global, envolvendo grande número de instituições financeiras e Estados. Logo após a falência do Lehman Brothers ${ }^{10}$, em setembro de 2008, uma restrição a créditos bancários foi imposta à Lituânia, à Estônia, à Latvia e à Islândia. O impacto da crise nesses países ocorreu devido aos seus elevados déficits em conta corrente e dívidas "em divisas", ou seja, tanto externas quanto internas. O FMI e a União Europeia lhes prescreveram uma política econômica de deflação. Os resultados foram uma queda, em 2009, do PIB em termos reais de 18,8\% na Latvia, de $15,7 \%$ na Estônia e de $11 \%$ na Lituânia ${ }^{11}$ (FARHI, 2010, p.17).

Agentes de mercado recusaram-se a elevar as proporções dos débitos públicos em suas carteiras, a fim de impedir a falência das economias nacionais. Essa reação colocou em xeque um dos pressupostos dos acordos de Basiléia ${ }^{12}$, instituindo que títulos públicos não possuíam riscos e que, portanto, não eram necessárias reservas de capital. A pressão pela aquisição dessas carteiras visava estimular, sobretudo, economias fracas na zona do euro, como a de Portugal, Irlanda, Grécia e Espanha, - pejorativamente chamados de PIGS, ou então PIIGS, incluindo a Itália (FARHI, 2010, p.18). Demais medidas de contenção dos reflexos da crise foram utilizadas por governos e bancos centrais. Elevados volumes de injeção de capital público na forma de assistência de liquidez às grandes instituições foram aplicados, assim como garantias aos depositantes e credores foram estabelecidas. Juntas, tais medidas visavam evitar a reprodução da grande depressão de 1929 (FARHI, 2010, p.16).

10 Lehman Brothers Holdings Inc. foi um banco de investimento e serviços financeiros, sediado em Nova Iorque e atuando globalmente no ramo de investimentos de capital, venda em renda fixa e gestão de investimento.

11 A Islândia iniciou formalmente os trâmites necessários para a sua adesão à União Europeia somente em maio de 2009.

12 Acordos de supervisão bancária assinados em Basiléia, na Suíça, que impôs regras a todos os bancos do mundo. 


\section{O BRASIL E A CRISE DO SISTEMA FINANCEIRO}

No governo de Fernando Henrique Cardoso (1995-2002), seguindo os exemplos dos governos de Fernando Collor de Mello e de Itamar Franco, o foco da gestão político-econômica foi o desenvolvimento da nação. A saída de um longo período de repressão impulsionou iniciativas respaldadas na democratização do país por meio da privatização, da abertura da economia para o capital estrangeiro, da inserção do princípio do mercado como agente organizador da economia e da flexibilização dos direitos historicamente conquistados pela classe trabalhadora. $\mathrm{O}$ projeto de desenvolvimento e democratização aferiu continuidade à tendência neoliberal mundial, via globalização da economia e dos meios de comunicação (NEGRÃO, n/d).

Após quase duas décadas de aplicação de tais políticas-econômicas no Brasil, a alta do juro no mercado internacional provocou aumento da dívida externa e, consequentemente, a desvalorização da moeda nacional em relação ao dólar. Algumas empresas, em destaque as atuantes nos setores de celulose, alimentos processados, açúcar e álcool apresentaram grandes prejuízos e decretaram falência devido, em grande parte, à queda nas exportações e à diminuição da taxa de lucro. O Brasil, neste momento, possuía uma gestão voltada à promoção do desenvolvimento econômico e social do país. Os governos de Luís Inácio Lula da Silva (2003-2010) e de Dilma Rousseff (2011-2014) investiram em ações sociais, como por exemplo, o Bolsa Família. Contudo, a abertura do mercado doméstico ao capital estrangeiro causou a contaminação de algumas empresas públicas e privadas com ativos tóxicos ${ }^{13}$.

Segundo a análise de Almeida (2010, p.61), embora tenha sido grave a repercussão da crise no Brasil, os impactos ficaram restritos aos setores da indústria e da agropecuária. O gasto público, gerenciado pelo governo de Dilma Rousseff, na preservação dos empregos nos setores de serviços, alimentos e bens industriais básicos, não impediu a onda de demissões de trabalhadores formais entre outubro de 2008 a

13 Ativos tóxicos podem ser considerados como dívidas dadas em garantia de outras dívidas mais fluídas, maiores e mais distantes dos valores originais. 
março de 2009, somando cerca de 690 mil postos de trabalho. As demissões ocorreram na indústria (493 mil) e agropecuária (227 mil), mas não no comércio, que contratou no mesmo período 47 mil e em serviços, 67 mil trabalhadores (ALMEIDA, 2010, p.61).

A garantia da manutenção de uma média razoável de empregos estabilizou a inadimplência no sistema creditício familiar, suscitando reação competitiva por parte do segmento privado. No segundo trimestre de 2009 voltou a crescer a oferta de crédito para as pessoas físicas e, posteriormente, para as empresas. Algumas medidas relacionadas à política de crédito e financiamentos foram implementadas pelo Banco Central do Brasil (BCB), visando à redução dos depósitos compulsórios e a permissão de sua diminuição por grandes bancos, se os recursos fossem usados na compra de carteiras de crédito de pequenos e médios bancos, em especial daqueles com problemas de liquidez.

O Comitê de Política Monetária (Copom) realizou uma série de cortes nas taxas de juros de curto prazo, significando uma importante redução de cinco pontos percentuais em nove meses (MENDONÇA e DEOS, 2010, p.64). Medidas como a desoneração de impostos do ramo automobilístico, por meio da isenção do IPI, estimularam as vendas e a produção. Subsídios à construção civil, considerado um dos setores mais dinâmicos e multiplicadores da economia brasileira, foram ofertados. Cortes sucessivos nas taxas básicas de juros estimularam novos investimentos, assim como a redução das alíquotas de reservas compulsórias impulsionou a oferta de crédito.

O Banco do Brasil (BB) elevou a concessão de crédito a consumidores e empresas, principalmente nos segmentos relacionados ao comércio exterior e rural, atenuando os efeitos da sua diminuição pelos bancos privados. Intensificou a compra de carteiras de crédito de pequenas instituições bancárias, em consonância com a política promovida pelo BCB. Adquiriu ou finalizou o processo de aquisição de três bancos estaduais: Nossa Caixa Nosso Banco, Banco Estadual de Santa Catarina e Banco do Piauí, e assumiu grande participação no Banco Votorantim. Em outra frente, o BB promoveu cortes nas taxas de juros, - diminuindo o spread $^{14}$-, de várias modalidades de empréstimos, aumentando sua participação no mercado creditício. Desse modo,

14 Processo em que o banco empresta dinheiro, cobrando uma taxa de juros superior à taxa de captação. A diferença entre as duas taxas é chamado de spread bancário. 


\section{T

observou-se a importância das instituições financeiras públicas brasileiras que, controladas pelo governo federal, detinham em dezembro de 2009 39,9\% dos ativos do sistema financeiro e eram responsáveis por 43,5\% do volume de crédito (MENDONÇA e DEOS, 2010, p.65).

Contudo, de acordo com Terra e Silva (2010, p.84), a ação do governo de Dilma Rousseff não se processou a fim de prevenir a crise, mas de mitigar os efeitos nefastos e inexoráveis que dela emergiriam sobre a economia brasileira. Na opinião dos autores, a característica "socorrista" da atuação governamental pode ser explicada pelo perfil de atrofia da intervenção econômica estatal no Brasil pós-Plano Real e pela leitura míope do governo sobre a crise, seja pela superestimação dos fundamentos da economia brasileira, seja pela consideração de que a crise não passaria de uma "marolinha".

Na opinião de Sampaio Jr. (2009, p.95), a exposição da economia brasileira à fúria da concorrência em tempos de crise nos leva a explorar vantagens competitivas e absolutas ${ }^{15}$ por não conseguirmos competir com a dinâmica das economias centrais. Na divisão internacional do trabalho que se desenha, o Brasil pode assumir a posição de mero fornecedor de produtos primários e semimanufaturados, de baixo conteúdo tecnológico, alto consumo de energia e elevado impacto negativo sobre o meio ambiente. Tal fato caracterizaria a inserção passiva da economia brasileira na globalização dos negócios como processo de regressão industrial e de especialização.

\section{ANÁLISE MARXISTA DA CRISE FINANCEIRA}

Numa perspectiva marxista, estratégias para enfrentamento da crise pautadas em Keynes oferecem soluções reformistas, e não propostas de superação do capitalismo. Maior intervenção e regulação da economia pelo Estado e a garantia do pleno emprego são paliativos dos conflitos e antagonismos de classe. Nessa lógica, o capitalismo produz suas próprias crises e formas de superá-las, sem que sua essência seja perdida.

15 De modo geral, na teoria das vantagens absolutas, Adam Smith afirmava que as nações deveriam se especializar na produção para o qual estavam mais aparelhadas, trocando os excedentes entre si. Já na teoria das vantagens comparativas de David Ricardo defendia-se que um país deveria especializar-se na produção com mais baixo custo. 
Uma das soluções reformistas encontradas para a superação da crise nas décadas de 1970 e 1980 foi a modificação dos processos produtivo e acumulativo. Como já explicado anteriormente, a aplicação de capital no mercado financeiro com a compra de ações e títulos possibilitaram rendimentos a partir do recebimento do juro, sem o envolvimento direto com a produção. Tal processo, denominado por Marx "capital fictício”, gera uma fração de valor antes mesmo de esse ser produzido (MARX, 1988). Dessa forma, a financeirização, assumindo papel central no capitalismo contemporâneo, sustenta a transnacionalização da produção, facilita a concentração de renda e riqueza e apoia a hegemonia política do neoliberalismo por meio de ameaças contínuas de fuga de capital (SAAD FILHO, 2009, p.8). Segundo Carcanholo (2009, p.76) foi a disfuncionalidade do capital fictício que provocou a crise estrutural do capitalismo no início do século XXI.

Nos moldes do sistema capitalista, as políticas de austeridade são consideradas estratégias de enfrentamento da crise no sistema financeiro. Elas consistem ao aumento da exploração do trabalho com arrocho salarial, à flexibilização e/ou eliminação dos direitos trabalhistas, ao aumento do número de privatizações e à redução dos gastos públicos com projetos sociais. Estados intervieram nas dívidas de bancos e empresas com problemas de liquidez e solvência, lançando mão de títulos públicos e, por conseguinte, aumentando suas dívidas internas. De acordo com Carcanholo (2009, p.82), o provimento de liquidez aos mercados financeiros torna-se papel do Estado se este estiver inserido na lógica capitalista. Se assim constar, o Estado torna-se mais um instrumento de dominação de classe. Tal constatação é encontrada originalmente em Marx (n/d) no livro “As lutas de classe na França de 1848 a 1850”.

Quatro trilhões de dólares, aproximadamente, destinaram-se ao salvamento de instituições financeiras na crise de 2008. Esse valor é quarenta vezes o gasto no combate à pobreza e às mudanças climáticas no mundo. Quase US\$ 152,5 bilhões foram desembolsados pelo governo dos Estados Unidos no resgate de uma só empresa, a AIG, sendo que aquele país, junto aos europeus, destinou cerca de US\$90,7 bilhões de ajuda pró-desenvolvimento em 2007 (RIZVI, 2008, n/p).

A Organização Internacional do Trabalho (OIT), em estimativa do impacto da crise no cotidiano das pessoas, constatou que o número de desempregados pode

Em Tese, Florianópolis, v. 10, n. 2, jul./dez., 2013. ISSN: 1806-5023 


\section{Tese}

ultrapassar 200 milhões no mundo, pela primeira vez na história. Caso os efeitos do desaquecimento econômico não sejam rapidamente controlados, o número de pessoas recebendo menos de um dólar/dia deve aumentar em 40 milhões, e de pessoas vivendo com ganhos de apenas 2 dólares/dia, em 100 milhões (SOMAVIA, 2008, n/p). Nesse sentido, constata-se que, principalmente os Estados Unidos, a Grécia, a Espanha e Portugal convivem com a reversão dos ganhos sociais das últimas décadas. As ações destes governos, impondo o custo da crise para a classe trabalhadora, causam implicações profundas nos padrões de vida, aumentando os conflitos sociais.

Para Husson (2008, n/p) a verdadeira solução seria por fim ao retrocesso salarial, modificar a distribuição das riquezas - menos lucros, mais salários - e intensificar os investimentos sociais. Tariq Ali (2012) concorda com as sugestões de Husson (2008), afinal, ambos acreditam que Wall Street havia previsto a crise e planejado a bolha imobiliária, veiculando campanhas publicitárias para estimular tomadores de crédito pessoal. De acordo com os autores, o auxílio financeiro dos governos às instituições financeiras também já era previsto. Tariq Ali designa esse fato como "socialismo para os ricos".

Irlandeses e franceses argumentaram que a circulação do capital de forma ampla e irrestrita no âmbito da União Europeia garantiria ao Banco Central Europeu ações independentes das relações políticas dos Estados-Membros. Contudo, a responsabilidade sobre o desempenho econômico e social ficou a encargo dos Estados Nacionais e o Estatuto do Banco Central Europeu impediu o banco de articular crédito ou socorro aos Estados-Membros em dificuldades. Saad Filho (2009, p.16) acredita na necessidade de estatização do sistema financeiro e sua transformação num serviço de utilidade pública, afinal, se perdas precisam ser socializadas, então não há justificativas para a existência de lucros nesse setor. Contudo, a contradição se exprime na atitude das classes dominantes que, apoiadas no keynesianismo de circunstância, recebem amparo nas suas instituições financeiras e esperam que as concessões da classe trabalhadora recoloquem o neoliberalismo revigorado no caminho do progresso (DUMÉNIL e LÉVY, 2009, p.66).

Para Duménil e Lévy (2009, p.67), vivemos a política do imobilismo, caracterizada principalmente pela tentativa de conjugar estratégias neoliberais com

Em Tese, Florianópolis, v. 10, n. 2, jul./dez., 2013. ISSN: 1806-5023 


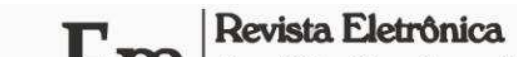

políticas de cunho keynesianas. As ações na lógica do neoliberalismo preveem: 1) O rápido retorno ao equilíbrio orçamentário com medidas de austeridade. Os defensores dessa linha são hostis aos impostos, no entanto, se o aumento destes é inevitável, preferem os indiretos e rejeitam a progressividade em função dos rendimentos das famílias; 2) $\mathrm{O}$ aprofundamento das imposições às classes populares em matéria de trabalho, de rendimentos, de proteção social e de educação; e 3) A defesa de políticas anti-estatais. Já as ações pautadas no marco keynesiano trazem como fundamentais: 1) A ponderação entre os objetivos de controle dos déficits e de manutenção da atividade econômica; 2) A disposição de compartilhar, entre os setores público e privado, os encargos criados pela crise; e 3) A regulamentação e o papel crescente organizador do Estado em relação à economia. Desse modo, a corrente keynesiana modera a implementação das ações da corrente neoliberal, mas não possui os meios de executar suas próprias políticas; daí o imobilismo reinante.

A estratificação e a luta de classes continuam sendo a principal característica fundante do capitalismo, mesmo intermediadas por instâncias como o Estado, segundo Carcanholo (2009, p.84). Utilizar-se delas sempre que possível é uma arma, pois, não se pode desconsiderar que o principal sujeito anticapitalista continua sendo a classe que mais sofre as consequências levantadas anteriormente. Nesse sentido, deve-se aproveitar o aumento das confrontações sociais em escala mundial. "Se essa classe trabalhadora vai tomar consciência de si (e para si), propor-se a construir uma alternativa concreta anticapitalista, e essa proposição vai se efetivar historicamente, é algo que só a História poderá nos mostrar" (CARCANHOLO, 2009, p.84).

Modelos alternativos ao neoliberalismo ainda têm existências regionais, como nos casos da América Latina e, de outra maneira, da China, de acordo com Emir Sader (2012). O autor acredita que América Latina tenha dado passos importantes, confirmando a capacidade de resistência do Sul do mundo. Nesse sentido, Tariq Ali fala sobre as lutas dos países sul-americanos:

O modelo das rebeliões sul-americanas contra o neoliberalismo e suas instituições globais nos diz muito neste sentido. As imensas e exitosas lutas contra o FMI na Venezuela, contra a privatização da água na Bolívia e contra a privatização da eletricidade no Peru, criaram a base de uma nova política que triunfou nas urnas nos dois primeiros países, bem como no Equador e no 


\section{Tese}

Paraguai. Uma vez eleitos, os novos governos começaram a por em marcha as reformas sociais e econômicas prometidas, com diversos graus de êxito (ALI, 2012, n/p).

As mobilizações em diversas partes, incluindo jovens empregados e operariado precário, trabalhadores desempregados, estudantes de graduação endividados, veteranos de guerra, sindicalistas, pobres, profissionais liberais, anarquistas, hippies, juventude desencantada, compõem uma consciência coletiva de luta e protesto que, mesmo difusa, volta-se à solidariedade mútua e conjuga as lutas antes fragmentadas (ALVES, 2012, p.32). Iniciando no norte da África, derrubando ditaduras na Tunísia, no Egito, na Líbia e no Iêmen; estendeu-se à Europa, com ocupações e greves na Espanha e Grécia, e revolta nos subúrbios de Londres. Eclodiu no Chile e ocupou Wall Street, nos EUA, alcançando até mesmo a Rússia (CARNEIRO, 2012).

Diversas análises começam a surgir sobre os novos movimentos sociais, em destaque o movimento Occupy Wall Street e suas estratégias de ação. Algumas críticas relacionam-se a não incorporação de utopias grandiosas de emancipação social, que exigem clareza politico-ideológica. Segundo Alves (2012, p.36), não podem ser considerados como movimentos anticapitalistas, mesmo criticando o capitalismo como modo de produção da vida. Na opinião do autor, o que predomina é um modo de consciência contingente capaz de expor, com indignação moral, as misérias do sistema sociometabólico do capital, mas sem identificar suas causalidades histórico-estruturais.

Para Wallerstein (2012), pela primeira vez, em muito tempo, pessoas comuns passaram a discutir a natureza do sistema no qual vivem, pois já não o veem como natural ou inevitável. Zizek (2012) alerta para a necessidade de se resistir, nesta primeira etapa, ao desejo de traduzir a luta em uma série de demandas pragmáticas e concretas. A abertura para o novo e o preenchimento do vazio da ideologia hegemônica necessita de tempo. Vivemos num momento em que precisamos refletir sobre qual democracia queremos. De acordo com Zizek, não devemos esquecer o que escreveu Gilbert Keith: "Ter uma mente aberta, em si, não é nada; o objetivo de abrir a mente, como o de abrir a boca, é poder fechá-la com algo sólido dentro" (ZIZEK, 2012, n/p).

Correntes que almejam a superação do capitalismo necessitam estabelecer acordos, fazendo com que esperanças emergidas em tempos de crise não sejam 


\section{Tese}

dissipadas. A esquerda mundial precisa melhorar sua unidade política e definir com clareza seus objetivos de curto e longo prazo. Um importante ponto de discordância diz respeito às eleições. Um grupo afirma que são politicamente ineficazes e que reforçam a legitimidade do sistema mundial existente. Outro grupo acha que é crucial participar de processos eleitorais e trabalhar de dentro dos maiores partidos de centro-esquerda num sistema multipartidário funcional, ou dentro do partido único, quando a alternância parlamentar não é permitida. Outra parte ainda prefere a escolha do mal menor, votando em representantes que estejam "genuinamente" na esquerda. Outro impasse encontra-se na opção pelo desenvolvimentismo e por prioridades na mudança da civilização. A opção desenvolvimentista, quando apoiada por governos de esquerda ou sindicatos, sustenta que sem crescimento econômico não é possível enfrentar as desigualdades. Esse grupo é acusado de apoiar os interesses da base direitista. Os que apoiam a opção anti-desenvolvimentista dizem que o foco do crescimento econômico está errado, pois os danos sociais e ambientais causados por ele são irreparáveis (WALLERSTEIN, 2012).

Alves (2012, p.37) afirma que hoje, mais do que nunca, o método dialético tornou-se indispensável no exercício da crítica social. Os cientistas sociais devem analisar os novos movimentos sociais na perspectiva da lógica dialética, apreendendo a riqueza do movimento contraditório do real, ou seja, a dialética cadente entre subjetividade e objetividade, alcances e limites, contingência e necessidade, barbárie e civilização. Nesse sentido, o retorno à análise de Marx sobre o capitalismo e seu lugar na evolução histórica da humanidade ganha espaço. De acordo com Musto (2008, n/p), nenhum marxista poderia acreditar que o capitalismo liberal havia triunfado para sempre, que a história havia chegado ao fim ou que qualquer sistema de relações humanas pudesse ser definitivo.

Arcary (2009, p.125) afirma ser possível a superação da atual crise. Esta dependerá do curso da luta de classes e, se derrotada, sofrerá os custos de uma regressão econômica e social. Para o autor, quando uma ordem econômica, social e política é incapaz de realizar mudanças, a partir de negociação ou reformas, as forças sociais interessadas recorrem aos métodos da revolução para reivindicar. A hipótese do autor é que a urgência da revolução voltou a ter significado político imediato. Contudo, isso 


\section{Tese}

não significa que o socialismo está próximo, pois a luta por ele requer mais do que ações revolucionárias contra o governo e regime, exige protagonismo proletário independente e projeto internacionalista.

\section{ALTERNATIVAS ECONÔMICAS E RUPTURA COM A VELHA ORDEM}

$\mathrm{Na}$ análise de Singer, atual secretário da Secretaria Nacional de Economia Solidária (SENAES) ${ }^{16}$, as contradições do capitalismo criam oportunidades para o desenvolvimento de organizações econômicas cuja lógica é oposta ao modo de produção dominante. Diante das dificuldades incitadas pelas políticas de austeridade dos governos afetados pela crise do sistema financeiro, da alta concentração de capital e da estagnação econômica, algumas comunidades passam a enxergar a Economia Solidária e as Finanças Solidárias como estratégias para geração de renda e desenvolvimento local. Alternativas que conferem dinâmica de circulação ao capital, como as moedas sociais, tornam-se frequentes. Impulsionadas pelos sistemas de informática e pelo início do colapso do sistema monetário global, essas moedas também foram pensadas para gerar fluxo de caixa, um problema vivenciado pelas pequenas empresas na crise de 2008.

A moeda social, criada e operada por associações autogestionárias, torna-se um importante instrumento na viabilização de troca de bens e serviços. Espaços específicos, como os Clubes de Trocas, são planejados para realização de negócios. Pessoas que vivenciam no mais alto grau a crise estrutural do capital podem trabalhar umas para as outras, satisfazendo suas necessidades e vivenciando novas relações sociais baseadas na ajuda mútua. Assim, algumas experiências tidas a partir de Clubes de Trocas e da criação de Bancos Comunitários para emissão e controle das moedas sociais fortalecem as comunidades e proporcionam novas reflexões acerca do consumo e do dinheiro.

O microcrédito poderia fortalecer, por meio de fomento financeiro, iniciativas pautadas no cooperativismo e/ou no associativismo. No entanto, milhares de pessoas

16 Em 2003 foi criada a SENAES para viabilizar e coordenar a atividade no território nacional. 
que desejam acessar o microcrédito não comprovam renda, moradia e adimplência financeira, inviabilizando a transação do empréstimo e a realização de projetos voltados à geração de renda.

Para auxiliar na compreensão da distribuição do crédito e do microcrédito, Singer (2009, p.69) discorre brevemente sobre o sistema financeiro, dividindo-o em três partes. A primeira parte é a considerada capitalista, composta por intermediários financeiros, ou seja, bancos, companhia de seguros e corretoras, que têm por objetivo vantagens lucrativas. A segunda é a parte estatal, composta por bancos federais e estaduais, que não deveriam visar lucros e sim a prestação de serviços. A terceira parte trata-se de uma grande variedade de intermediários financeiros, dos quais uma parcela consta da chamada Finanças Social ou Solidária, que não visa lucro, mas o atendimento das necessidades das comunidades excluídas do acesso ao crédito.

Na parcela correspondente às Finanças Sociais ou Solidárias dois grupos são identificados. As Entidades de Microcrédito (EMCs), geralmente Organizações da Sociedade Civil e de Interesse Público (Oscips), oferecem crédito contra garantias morais - o chamado aval solidário - dado a clientes da mesma EMC, que mantêm laços de confiança e ajuda mútua. A legislação não autoriza o recebimento dos depósitos dos clientes pelas EMCs, assim, os fundos que emprestam são captados de fontes estatais ou de ajuda internacional. O outro grupo é composto por associações de poupança e crédito, baseadas nas cooperativas de crédito da Alemanha no século XIX. O capital da cooperativa, chamado de Fundo Rotativo, é formado por cotas dos sócios, o qual é emprestado exclusivamente a estes. Os Fundos Rotativos Solidários (FRS) ou Comunitários também recebem auxílio da igreja católica ou ajuda internacional. Nos últimos anos, têm recebido ajuda do Governo Federal por meio da parceria entre Banco do Nordeste do Brasil (BNB), SENAES, Ministério do Trabalho e Emprego (MTE) e Ministério de Desenvolvimento Social (MDS) (SINGER, 2009, p.71). A principal característica deste tipo de cooperativa é a autogestão, sendo as decisões tomadas coletivamente em assembleias. No entanto, por serem intermediários financeiros formalizados, são submetidos à supervisão e orientação do BC.

Como exemplo emblemático, articulado pela população do Conjunto Palmeiras em Fortaleza, Ceará, tem-se o Banco Palmas, inaugurado em 1998 com 


\section{Tese}

aproximadamente 40 associados. Com a criação de um cartão de crédito, o Palmacard, e o aumento dos estabelecimentos credenciados aceitando o cartão e a moeda social, o bairro tornou-se um grande Clube de Trocas. O lastro da moeda é baseado em reais, ou seja, cada Palma vale um Real, podendo, inclusive, ser trocado a qualquer momento. Dessa forma evitou-se o isolamento do comércio local, permitindo a entrada de fornecedores e a saída da produção para outras comunidades. Também, a fim de estimular o comércio e o superávit do Banco Comunitário, os estabelecimentos aumentaram a competição da moeda Palmas com descontos especiais para quem usasse a moeda social. Com o tempo, o Banco Comunitário Palmas passou a oferecer empréstimos, em Palmas ou em Real, a grupos solidários de produção.

Em 2005 a SENAES firmou parceria com o Banco Palmas, a fim de difundir os Bancos Comunitários em outras regiões do país. A experiência inspirou a criação do Banco PAR na cidade de Paracuru, a 70 km de Fortaleza. Em 2006, o Banco Popular do Brasil também se tornou parceiro do Banco Palmas, investindo dinheiro e ampliando suas possibilidades de atuação. No mesmo ano, a Petrobrás se une às parcerias, apoiando a multiplicação dos Bancos Comunitários pelo Brasil. Singer (2009, p.78) acredita que para o êxito de um Banco Comunitário, além das parcerias realizadas, a confiança mútua, a capacidade de ação coletiva e o preparo político são cruciais.

É importante considerar que a extensão dessas ações aos Empreendimentos Econômicos Solidários (EES) pode consolidar uma estratégia de enfretamento da crise estrutural. Não isentando os empreendimentos pertencentes à Economia Solidária - ou seja, cooperativas, associações, Bancos Comunitários entre outros - das influências exercidas pelo atual sistema na deturpação dos princípios que os regem, pode-se atrelálos a uma plataforma de desenvolvimento que tenha como perspectiva evitar a fuga do capital para o sistema financeiro e projetá-lo novamente à produção, proporcionando renda e desenvolvimento local.

Em grande medida, os EES são resultado da falência de empresas capitalistas, subutilização do solo por latifúndios e do desemprego em massa. Para Singer (2008), provavelmente nas próximas décadas o deslocamento dos postos de trabalho do centro da economia para a periferia perderá intensidade. Isso dependerá do ritmo de crescimento das economias nacionais, estimulado por novos padrões de consumo e pela

Em Tese, Florianópolis, v. 10, n. 2, jul./dez., 2013. ISSN: 1806-5023 


\section{Tese}

capacidade das potências dominantes de manterem alguma ordem no mercado financeiro global. Assim, se a Economia Solidária ascende em resposta às contradições do capitalismo, seu crescimento poderá se desacelerar no futuro, passando a ser uma forma complementar deste. Singer (2008) acredita que a Economia Solidária necessita desenvolver sua própria dinâmica ao invés de depender de uma "reatividade" às contradições do modo dominante de produção. $\mathrm{O}$ autor afirma que não se pode excluir a possibilidade de a economia capitalista conquistar uma nova fase "áurea" como ocorreu nos conhecidos anos dourados da segunda metade do século XX, onde se visualizou todos os benefícios deste sistema em detrimento de seus problemas estruturais e, se assim acontecer, esta concepção de Economia Solidária estaria fadada ao fracasso.

Uma das principais características dos EES é a autogestão. Por meio dela, os empreendimentos são geridos coletivamente através da cooperação, de relações solidárias entre os sócios, do compartilhamento das responsabilidades, da democracia com participação plena e da autonomia dos trabalhadores. A autogestão, entretanto, é um dos limites verificados por Veronese (2007) em pesquisa apresentada no Congresso Brasileiro de Sociologia. A autora constatou a existência de altos níveis de participação política e de apropriação do sentido da solidariedade nas práticas econômicas/produtivas/comerciais/organizacionais, relacionados a uma nova forma de viver, a uma ruptura com o passado de trabalhador explorado e a emergência de um sujeito em busca de emancipação. Contudo, em sua pesquisa também verificou o desconhecimento total do princípio da autogestão, evidenciado principalmente na passividade de alguns sócios diante da necessidade de tomada de decisões, e no despreparo para o exercício de uma postura ativa e autônoma.

Para evitar tal malogro seria necessário construir um sistema de geração e difusão de conhecimento, proporcionando formação técnica e ideológica aos futuros integrantes da Economia Solidária. Far-se-iam indispensáveis medidas que favorecessem uma economia inclusiva, assim como estratégias de proteção contra a competição capitalista por meio da motivação do consumo solidário, aumentando a demanda por bens e serviços provenientes dos EES. Em contrapartida, Singer (2008) alerta que, ao proteger as pequenas unidades solidárias de produção, o consumo

Em Tese, Florianópolis, v. 10, n. 2, jul./dez., 2013. ISSN: 1806-5023 


\section{Tese}

solidário lhes poupa a necessidade de se atualizarem tecnicamente, levando-as a acomodarem-se numa posição de inferioridade. Tal proposta teria sentido se as unidades produtivas e as comunidades de compra solidária se integrassem em rede e desenvolvessem padrões de consumo consideravelmente diferentes dos prevalecentes na economia capitalista.

Marx (1991, p.509) observa que as fábricas das cooperativas de trabalhadores no interior do regime capitalista são a primeira ruptura com a velha forma, embora reproduzam todos os defeitos do sistema capitalista. Em certo nível de desenvolvimento das forças produtivas materiais e das formas sociais de produção correspondentes, um novo modo de produção naturalmente desponta e se desenvolve partindo do antigo. Sem o sistema fabril oriundo do modo capitalista de produção, não poderia desenvolver-se a cooperativa industrial dos trabalhadores, por exemplo. Tanto empresas capitalistas por ações quanto as cooperativas industriais dos trabalhadores devem ser consideradas formas de transição entre o modo capitalista de produção e o modo associado, com a diferença que, no primeiro caso, a contradição é superada negativamente e, no outro, de maneira positiva (MARX, 1991, p. 509).

Contudo, os EES só terão sentido, enquanto estratégia de transição e superação, quando se tornarem tão importantes quanto à participação política nos assuntos do bairro, da cidade e do país. A luta econômica e a luta política devem estar unificadas, sendo que o exercício político pressupõe o fim da escravização social de toda uma classe. Nesse sentido, outro mundo é possível na medida em que se estabeleçam outras relações com o ambiente em que vivemos. Novos cenários estão em construção e a Economia Solidária e as Finanças Solidárias, por meio de suas práticas sociais, têm a possibilidade de produzir espaços diferenciados, menos desiguais e que ofereçam condições para outra forma de organização da vida coletiva. Os esforços assim destinados contribuem com a construção da justiça social, considerando esta como a justa divisão da riqueza produzida por toda a sociedade.

\section{CONSIDERAÇÕES FINAIS}


Diante do atual contexto de crise, duas alternativas se colocam aos governos nacionais: reformar as políticas econômicas existentes, oportunizando a recuperação do atual sistema dominante, ou então investigar e aplicar projetos que promovam a transição e a superação da velha forma. Como exposto anteriormente, a esquerda encontra-se dividida em suas ações, embora mantenha horizonte similar. A premissa que coloca a Economia Solidária e as Finanças Solidárias como projetos de superação não é consenso. Acreditar que elas, por si só, podem transformar o atual sistema é tropeçar em barreiras que ainda necessitam ser superadas. No entanto, o que afirmo neste artigo é que tanto a Economia Solidária quanto as Finanças Solidárias podem contribuir para a reflexão acerca do projeto de sociedade que queremos defender e implementar.

Além de significarem uma alternativa de trabalho e geração de renda, podem revelar-se como estratégias no desenvolvimento das condições históricas necessárias para a transformação nos âmbitos social, econômico e político. A verdadeira transição está na realidade social, isto é, na manifestação dos movimentos sociais, na busca por novas formas de produção e distribuição da riqueza social. Tanto a Economia Solidária quanto as Finanças Solidárias podem impulsionar a edificação desta nova realidade, estimulando o desenvolvimento de relações sociais baseadas nos princípios da solidariedade, da democracia e da plena participação política.

\section{REFERÊNCIAS}

ALI, Tariq. “O espírito da época.” In: Occupy: Movimentos de protesto que tomaram as ruas. São Paulo: Boitempo; Carta Maior, 2012.

ALMEIDA, Júlio. "Como o Brasil superou a Crise" In: Associação Keynesiana Brasileira. Dossiê da Crise II. Agosto de 2010.

ALVES, Giovanni. “Ocupar Wall Street... e depois?” In: Occupy: Movimentos de protesto que tomaram as ruas. São Paulo: Boitempo; Carta Maior, 2012. 
ARCARY, Valério. "Os abismos regressivos da história: anotações sobre a crise econômica internacional (2008-2011)" In: Dossiê: A crise atual do capitalismo. Campinas: Crítica Marxista, n.29, 2009.

CARCANHOLO, Marcelo Dias. "Conteúdo e forma da crise atual do capitalismo: lógica, contradições e possibilidades" In: Dossiê: A crise atual do capitalismo. Campinas: Crítica Marxista, n.29, 2009.

CARNEIRO, Henrique Soares. “Apresentação." In: Occupy: Movimentos de protesto que tomaram as ruas. São Paulo: Boitempo; Carta Maior, 2012.

CARVALHO, Fernando Cardim de. O retorno de Keynes. Novos Estudos Cebrap, 83, março 2009.

"Entendendo a Recente Crise Financeira Global" In: Associação Keynesiana Brasileira. Dossiê da Crise. Novembro de 2008.

CINTRA, Marcos Antônio Macedo; FARHI, Maryse. "A arquitetura do sistema financeiro internacional contemporâneo" In: Revista de Economia Política, vol. 29, n.115, julho-setembro/2009.

DUMÉNIL, Gérard; LÉVY, Dominique. "Dívidas soberanas: Limites do receituário keynesiano para uma crise estrutural" In: Dossiê: A Crise Atual Do Capitalismo. Campinas: Crítica Marxista, n.29, 2009.

FARHI, Maryse. "Double Dip: A recuperação econômica em questão" In: Associação Keynesiana Brasileira. Dossiê da Crise II. Agosto de 2010.

FARHI, M.; PRATES, D. M.; FREITAS, M. C.P. de; CINTRA, M. A. M. A. "Crise e os Desafios para a Nova Arquitetura Financeira Internacional" In: Associação Keynesiana Brasileira. Dossiê da Crise. Novembro de 2008. 


\section{Tese}

HERMANN, Jennifer. "Da Liberalização à Crise Financeira Americana: a morte anunciada chega ao Paraíso" In: Associação Keynesiana Brasileira. Dossiê da Crise. Novembro de 2008.

HUSSON, Michel. Crise: salários contra lucros. Carta Maior, novembro de 2008.

MARX, Karl. O capital. T.I, vol.I. Círculo do Livro, 1996.

O Capital. L. 3, vol.V. São Paulo: Bertrand Brasil, 1991.

O Capital. Vols. IV e V, seções IV e V. São Paulo: Nova Cultural, 1988.

As lutas de classes na França de 1848 a 1850. In: Obras escolhidas:

Karl Marx - Friedrich Engels. Vol. 2. São Paulo: Alfa-Omega, n/d. Cf.: Disponível em: http://www.consultapopular.org.br/sites/default/files/As\%20Lutas\%20de\%20Classes\%2 0em\%20Fran\%C3\%A7a\%20de\%201848\%20a\%201850.pdf. Acesso em: 15/11/2013.

MENDONÇA, Ana Rosa Ribeiro de; DEOS, Simone. "O Papel dos Bancos Públicos e a Experiência Brasileira Recente" In: Associação Keynesiana Brasileira. Dossiê da Crise II. Agosto de 2010.

MUSTO, Marcello. A crise do capitalismo e a importância atual de Marx. Carta Maior, setembro de 2008 .

NEGRÃO, João José de Oliveira. O governo FHC e o Neoliberalismo. Cf.: Disponível em: www.pucsp.br/neils/downloads/v1_artigo_negrao.pdf. Acesso em 28/07/2012.

PALlEY, Thomas. "A Exaustão do Paradigma de Crescimento da Economia Americana” In: Associação Keynesiana Brasileira. Dossiê da Crise II. Agosto de 2010. RIZVI, Haider. Bancos recebem ajuda de US\$ 4 trilhões. E o resto do planeta? Carta Maior, novembro de 2008. 23/06/2012. 


\section{Tese}

SAAD FILHO, Alfredo. "Crise no neoliberalismo ou crise do neoliberalismo?" In: Dossiê: A Crise Atual Do Capitalismo. Campinas: Crítica Marxista, n.29, 2009.

SADER, Emir. “2011: crise capitalista e novo cenário no Oriente Médio” In: Occupy: Movimentos de protesto que tomaram as ruas. São Paulo: Boitempo; Carta Maior, 2012.

SAMPAIO JÚNIOR, Plínio de Arruda. "Metástase da crise e aprofundamento da reversão neocolonial" In: Dossiê: A Crise Atual Do Capitalismo. Campinas: Crítica Marxista, n.29, 2009.

SINGER, Paul. "Finanças Solidárias e Moeda Social" In: Projeto Inclusão Financeira: Perspectivas e desafios para Inclusão Financeira no Brasil: Visão de diferentes atores. Brasília: Banco Central do Brasil, 2009.

Introdução à Economia Solidária. $3^{\mathrm{a}}$ edição. São Paulo: Editora Fundação Perseu Abramo, 2008.

SOMAVIA, Juan. Número global de desempregados pode passar de 200 milhões. Carta Maior, outubro de 2008.

TERRA, Fábio Henrique Bittes; SILVA, Guilherme Jonas Costa da. "Prevenir é Melhor que Remediar: alternativas de políticas econômicas keynesianas para a prevenção de crises financeiras" In: Associação Keynesiana Brasileira. Dossiê da Crise II. Agosto de 2010.

VERONESE, Marília Veríssimo. "As possibilidades de constituição de uma liderança autogestionária em empreendimentos econômicos solidários” In: Congresso Brasileiro de Sociologia, XIII., 2007, Recife. Anais do XIII CBS, Recife, PE,: SBS, 2007. 


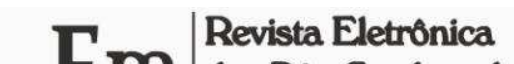

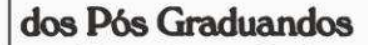

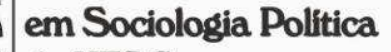 da UFSC}

WALLERSTEIN, Immanuel. “A esquerda mundial após 2011” In: Occupy: Movimentos de protesto que tomaram as ruas. São Paulo: Boitempo; Carta Maior, 2012.

ZIZEK, Slavoj. "O violento silêncio de um novo começo". In: Occupy: Movimentos de protesto que tomaram as ruas. São Paulo: Boitempo; Carta Maior, 2012. 


\title{
Tese
}

\section{RESUMO}

Neste artigo problematizo o sistema capitalista empregando análises marxianas referentes ao desenvolvimento de condições históricas na transição da velha forma. Exponho e analiso duas crises econômicas mundiais, a dos anos 1970-80 e a do sistema financeiro em 2008, utilizando-me da fala de diferentes autores marxistas. Discorro também sobre as consequências da crise de 2008 no Brasil e as ações do governo de Dilma Rousseff. Aponto alternativas no campo da Economia Solidária e das Finanças Solidárias, forjadas dentro e a partir do sistema capitalista, como estratégia de desenvolvimento das condições históricas necessárias para a transformação sócio/econômica/política, considerando seus alcances e limites.

PALAVRAS-CHAVE: Crises do sistema capitalista. Economia Solidária. Finanças Solidárias.

\begin{abstract}
In this paper I discuss the capitalist system employing Marxian analyses on the development of historical conditions for the evolution and transition from the actual economic system. I present and analyze two world economic crises, the first in the years 1970-80, and the financial system crisis in 2008, using texts of different Marxist authors. I also problematize the consequences of the 2008 crisis in Brazil and the actions of the government of Dilma Rousseff. I point to alternatives in the field of Solidarity Economy and Finance of Solidarity, forged within the capitalist system, as a strategy of development of necessary historical conditions for social, economic and political transformations, considering its scope and limits.
\end{abstract}

KEYWORDS: Crises of the capitalist system. Solidarity Economy. Solidarity Finance.

Recebido em: 11 de julho de 2013

Aceito para publicação em: 14 de setembro de 2013

Em Tese, Florianópolis, v. 10, n. 2, jul./dez., 2013. ISSN: 1806-5023 